\title{
Erratum to: A target-oriented data envelopment analysis for energy-environment efficiency improvement in Japan
}

\author{
Soushi Suzuki • Peter Nijkamp • Piet Rietveld
}

Published online: 4 November 2014

(C) Springer Science+Business Media Dordrecht 2014

Erratum to: Food Security (2014)

DOI 10.1007/s12053-014-9297-z

Due to the decease of one of the co-authors of the article "A Target-Oriented Data Envelopment Analysis for Energy-Environment Efficiency Improvement in Japan" (Energy Efficiency, DOI: 10.1007/s12053-014-9297-z), its publication was delayed. Consequently, a few references to recent work of the authors need to be updated as follows:

- Kourtit, K., Nijkamp, P., Suzuki, S. (2012) The Rat Race between World Cities: In Search of Exceptional Places by Means of Super-Efficient Data Development Analysis. Computers, Environment and Urban Systems 38: 67-77.

- Suzuki, S. and Nijkamp, P. (2011), A StepwiseProjection Data Envelopment Analysis for Public Transport Operations in Japan, Letters in Spatial and Resource Sciences, 4(2): 139-156.

The online version of the original article can be found at http://dx. doi.org/10.1007/s12053-014-9297-z.

S. Suzuki

Department of Life Science and Technology, Hokkai-Gakuen

University, Sapporo, Japan

P. Nijkamp $(\bowtie) \cdot$ P. Rietveld

Department of Spatial Economics, VU University

Amsterdam, Amsterdam, The Netherlands

e-mail: p.nijkamp@vu.nl 